\title{
DEBRIS AND VESSEL TRANSPORT DUE TO TSUNAMI CURRENTS IN PORTS AND HARBORS
}

\author{
Aykut Ayca, University of Southern California, ayca@usc.edu \\ Patrick Lynett, University of Southern California, plynett@usc.edu
}

\section{INTRODUCTION}

The focus of the discussion will be on the debris and vessel transport capacity of the tsunami induced currents in ports and harbors. The tsunami events in the past 15 years proved that understanding these processes within the port/harbor basin has paramount importance in safety, recovery and the long-term resilience planning of the facilities; as all of these depend on the ability of structures or infrastructure to resist damage and the capability of harbors to become functional after the event. This endeavor requires an accurate representation of the flow field around the floating objects. Particularly, when the size of an average container ship is considered among with its' fairly high draft to depth ratio, the interaction between flow and the vessels gets stronger. Therefore, in this study, the developed numerical tool, which is coupled with a $2 \mathrm{HD}$ nonlinear shallow water model, takes the interaction between the flow and the objects into account, and provides accurate results in a computationally efficient way.

We will also present example simulation results of a numerical modelling study aimed at providing the quantitative guidance on maritime tsunami hazards in ports and harbors. This information can be used in predisaster recovery planning with the identification of the safe mooring spots or where the debris will likely accumulate after future tsunamis. Whilst the harbor's ability to resist damage is a function of reducing the exposure to hazardous conditions as well as the maintaining/upgrading the structures/infrastructure within the harbors.

\section{TRANSPORT MODEL}

Here, the flow-object interaction is achieved by defining the floating objects in the hydrodynamic calculations as horizontal pressure distributions (Ertekin et. al., 1986). This horizontal pressure distribution is expressed as an additional forcing term forcing term in the momentum equations.

This approach has been applied widely in the past in modeling the waves generated by moving pressure distributions, and as this study concerned its' validity was verified through a numerical benchmark problem created in OpenFOAM, which will also be discussed.

In the transport model, the drag forces and the moments drive the linear and the angular accelerations of a stationary object. The motion of the fluid associated with these accelerations produces the ship to move with an equivalent added mass and inertia, which reflects the build-up of the kinetic energy of the fluid as the hull moves through it, acting as the restoring dynamics. Likewise, consideration of the viscous damping as a restoring element is also important, especially in the case of free motions, where the objects drift off.

\section{HYDRODYNAMIC MODEL}

Hydrodynamic inputs for the debris and vessel transport models presented in this study come from the application of the 'Method of Splitting Tsunami' (MOST) numerical model. The MOST model has been used extensively for tsunami hazard assessments in the United States and is currently in operational use at NOAA's Pacific Marine Environmental Laboratory (PMEL). Variants of the MOST model have been in constant use for tsunami hazard assessments in California since the mid 1990's.

\section{RESULTS}

The developed model has been validated through several available lab experiments. An example of these validations is shown in Figure 1, where one of the passing ship analysis that had been reported by Pinskter (2004) was recreated. We found that the model can calculate the forces exerted on moored ship by the passing ship at a reasonable extent. Yet, we also need to note here that the results are very sensitive to the shape of the pressure distributions assumed.
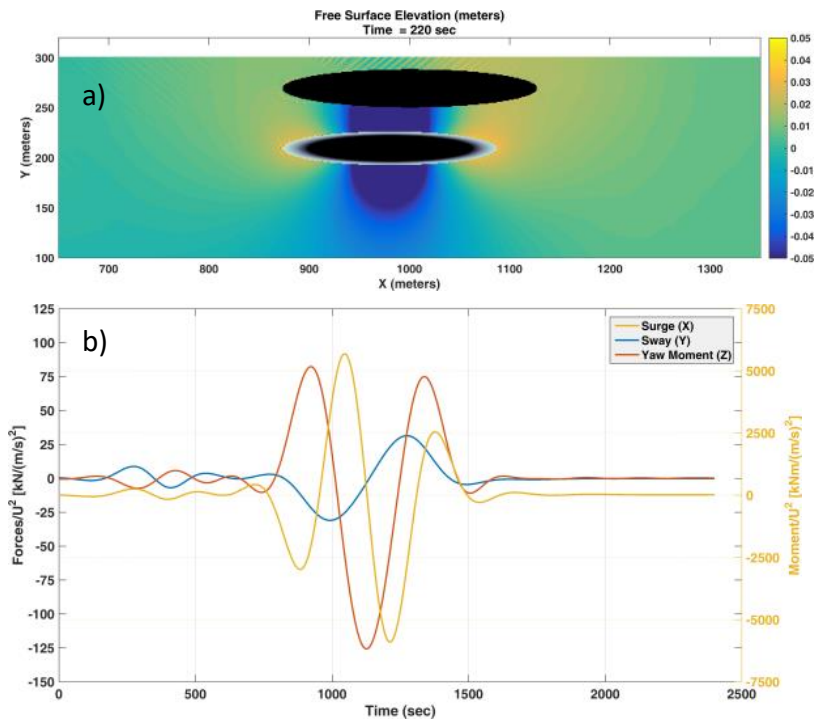

Figure 1 - a) FSE generated by the passing ship near the moored ship, b) Surge, Sway forces and yaw moment exerted on the moored ship by the passing ship

\section{REFERENCES}

Ertekin et. al., (1986). Waves caused by a moving disturbance in a shallow channel of finite width. J. Fluid Mech., 169, 275-292.

Pinskter J. A., M. N. Rujiter, The Influence of Passing Ships on Ships moored in Restricted Waters, Offshore Technology Conference 2004. 